ciated, in any individual, with a tendency to lack of vividness in other senses. The results of Betts are certainly the most adequate so far published for examining this question, and the positive correlation is clear enough to settle the question. The Pearson coefficient of correlation, when calculated as between the vividness of imagery of each sense with that in each other sense, averaged as follows: In a class of 34 college students of psychology, +0.68 ; in an 'extension' class of 45 students, mostly school teachers, +0.43 ; and in a group of 18 ' psychologists,' comprising teachers and graduate students of the subjects, +0.79 . Now there is no doubt one reservation to be made: since it is impossible to compare directly the images of different individuals, the result is dependent on each individual's conception of the meaning of a vivid image and of the scale of vividness; and it is easy to show, in untrained subjects, that this conception is subject to considerable error. Thus, the reviewer has found individuals who, on first answering Galton's questionnaire, assigned to their images the highest degree of vividness, but who, after further discussion, actually reduced their grade to near the zero of the scale. With this diffculty in mind, we might be inclined to read Betts's result as simply indicating that individuals differ in their resistance to the natural tendency to rank themselves high in imagery. But this suspicion cannot be upheld in the face of the specially high correlation existing within the expert group. If any of the existing testimony regarding imagery has scientific value, that secured by the present author is certainly entitled to precedence, and the positive correlation appearing in his results must be regarded as established till very good evidence is presented to the contrary. ${ }^{1}$

R. S. W.

\title{
TESTS OF GENERAL INTELLIGENCE.
}

Experimental Tests of General Intelligence. CrriL BurT. Brit. J. of Psychol., I909, III., 94-177.

This is the report of an admirable investigation on the measurement of 'general intelligence.' Its original purpose was to test the mathematical methods of Spearman, and to verify the experimental results of both Spearman and Meumann. Three specific problems were set: (I) Can the presence of general intelligence be detected and its amount measured? (2) "Can its nature be isolated and its meaning analysed?" (3) Is it predominantly an inherited_quality or is it due mainly to environmental influences?

Twelve tests were employed which group themselves under five heads : Sensory tests (discrimination of two points upon the skin, of

${ }^{1} \mathrm{Cf}$. Pyschological, BULLETIN, March, Igro, pp. 88 ff. 
lifted weights, of pitch, and of length of line by the eye), motor test (tapping and card dealing), sensori-motor tests (card sorting and alphabet finding), association tests (inmediate retention of words and syllables, mirror writing, and 'progressive apperception'), a test of voluntary attention (dotting irregular dots). These tests were performed upon two quite different groups of boys, twelve and a half to thirteen and a half years old, from two Oxford boys' schools. One group of thirty boys belonged to an elementary school which is attended by sons of the lower middle class. The other group of thirteen boys came from a preparatory school which is attended by boys from educated and intellectual families. The tests were made, apparently with a great deal of care, upon each boy individually.

The general intelligence of the boys was estimated by three independent rankings, one by the headmaster, one by the classmaster and one by two school fellows. These three were then compiled into one list. Coefficients of correlation were computed, by Spearman's footrule method, between each test and general intelligence, also between each test and every other test. The following are the coefficients between intelligence and each test : dotting .85 , progressive apperception $.8_{3}$, mirror $.7 \mathrm{r}$, memory $.7 \mathrm{r}$, alphabet finding $\cdot 79$, sorting .76 , dealing .30 , tapping .53 , pitch discrimination .46 , estimation of lines .47 , lifting weights -.ro. Six of these coefficients are below .50 and six above .50 . The former are derived from the simple sensory and motor tests while the latter are the correlations between the intelligence and the higher mental functions. On the basis of these, Burt suggests that "by means of some half dozen tests, we are able independently to arrange a group of boys in an order of intelligence, which shall be decidedly more accurate than the order given by scholastic examinations, and probably more accurate than the order given by the master." With regard to the inheritance of intelligence it seems that the two groups of boys are too small to allow a valid comparison. The tests however show that "with two exceptions the average performance of the boys of the preparatory school are all superior to those of the boys of the elementary school."

Daniel Starch.

UNIVERSITY OF WISCONSIN.

\section{AN EXPLANATION OF HAMLET'S MYSTERY.} The OEdipus Complex as an Explanation of Hamlet's Mystery. A Study in Motive. Ernest Jones, M.D. Amer. Jour. of Psych., I910, XXI., 72-113.

The paper is an exposition of an hypothesis suggested by Freud in a footnote of his Traumdeutung. Hamlet's inability to avenge the 